\title{
||||||||||||||||||||||||||||||||||||||||||||||||||||||||||||||||||.
}

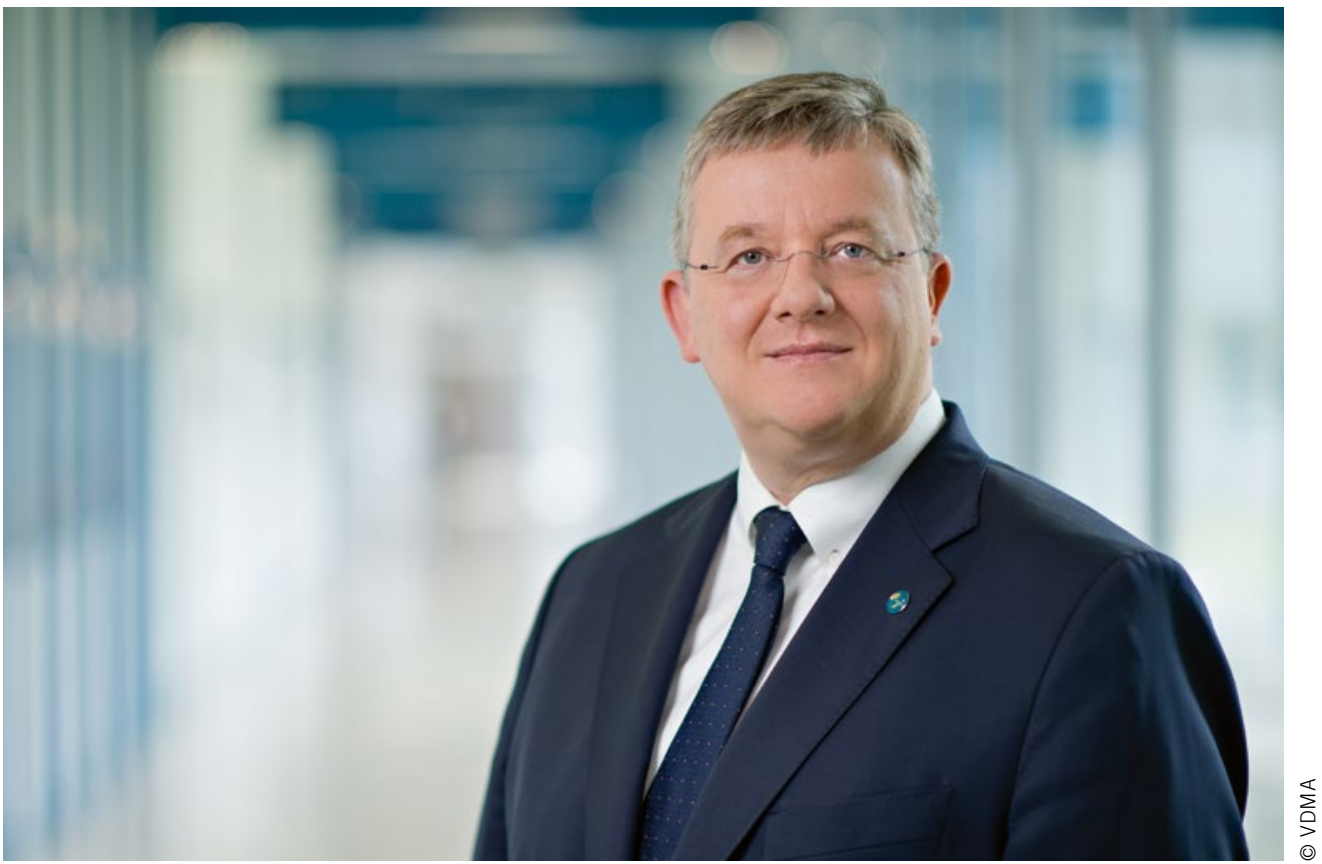

Dipl.-Kfm. Thilo Brodtmann Hauptgeschäftsführer des Verbands Deutscher Maschinenund Anlagenbau e. V. (VDMA)

\section{Fünf Maßnahmen statt 5000 Euro}

Der Klimagipfel von Paris gilt als Durchbruch im internationalen Klimaschutz. „Dekarbonisierung“ war die Botschaft. Für eine Volkswirtschaft wie die deutsche, die sich durch innovative und effiziente Produkte auszeichnet, bedeutet das eine große Chance, die zugleich jedoch die Größe der Herausforderung nicht verschweigen darf. Das gilt auch für die Elektromobilität, für die eine Kaufprämie von 5000 Euro debattiert wird.

Der Maschinenbau, die Automobilindustrie und die Elektrotechnik sind bestens aufgestellt, um Deutschland zum elektromobilen Leitmarkt und -anbieter zu machen. Gleichzeitig reden wir beim Thema Mobilität über eine tragende Säule unseres wirtschaftlichen Erfolgs. Jede Idee sollte daher den Test bestehen, ob sie Teil eines Konzepts oder bloß politischer Aktionismus ist.

Die Zahlen lassen an der versprochenen Wirkung einer Prämie zweifeln. Der politisch gesetzten Vorgabe von einer Million Elektrofahrzeugen in Deutschland bis 2020 stehen bislang real nur rund 100.000 batterieelektrische Autos und Plug-in-Hybride gegenüber. Diese Lücke wird sich nicht mit Subventionen füllen lassen. Bislang gibt es „elektromobile Pioniere“ - mehr nicht. Im Jahr 2020 werden rund 50 \% der Primärenergie für den Verkehr gebraucht. Ohne schlüssige Verknüpfung von Energiewende und Verkehr bleibt der Klimaschutz ein gut gemeinter Ansatz. Daher muss zum Beispiel gewährleistet werden, dass der Strom aus den Ladesäulen für Elektrofahrzeuge wirklich „grüner" Strom ist. Die debattierte Kaufprämie für Elektroautos wäre jedoch eine Einzelmaßnahme und kein intelligenter Baustein einer Gesamtlösung.
Zudem droht eine Kaufprämie an der eigentlichen Herausforderung zu scheitern. Sicher: 5000 Euro im Handschuhfach nimmt jeder gern mit. Wirklich erschwinglich werden die meisten Fahrzeuge damit jedoch nicht. Und das Motto „Wer es sich jetzt schon leisten kann, bekommt noch was dazu“ ist wenig zielführend. Die Fragen nach der erzielbaren Reichweite oder der Ladeinfrastruktur verweist auf fundamentalere Probleme. Was also tun?

Der VDMA schlägt fünf Maßnahmen vor. Erstens: Wir sollten unsere enormen Effizienzfortschritte beim Verbrennungsmotor nicht kleinreden. Es geht um einen Übergang in das elektromobile Zeitalter, keinesfalls um einen radikalen Schnitt. Zweitens: Wir müssen endlich Energiewende und Mobilität konzeptionell zusammenführen. Darin stecken enorme technische Potenziale, die wir für uns erschließen und vermarkten können. Drittens: Für Ballungsräume und ländliche Regionen wird es ganz unterschiedliche Optionen geben. Öffentlicher und individueller Verkehr wachsen schon jetzt in Städten wie Berlin zusammen, dort lassen sich weitere elektromobile Konzepte rascher umsetzen. Viertens: Wir müssen Mitnahmeeffekte vermeiden. Zwei Drittel aller Neuzulassungen entfallen auf gewerblich genutzte Fahrzeuge. Eine Sonderabschreibung (statt einer Kaufprämie) hätte hier eine zielgerichtete Anreizfunktion.

Und Fünftens: Es geht um Wettbewerbsfähigkeit durch reale Kostenreduktion. Der Schlüssel liegt hier in der Forschung, vor allem in den Bereichen der Produktions-, Batterie- und Antriebstechnik. 